\title{
THE RELIANCE OF THE CZECH ECONOMY ON ITS AUTOMOTIVE SECTOR
}

Mareš, D., Janíčko, M.

David Mareš / University of Finance and Administration, Faculty of Economic Studies, Department of Finance, Estonská 500, Prague, Czech Republic. Email: mares.dav@volny.cz

Martin Janícko / Prague University of Economics and Business, Faculty of Economics, Department of Economics, nám. W. Churchilla 1938/4, Prague, Czech Republic. Email: janicko@mnd.cz

\section{Abstract}

This paper explores the relationship between the performance of the Czech automotive industry and the performance of the Czech macroeconomy with an objective to fill in some existing gaps in the research on this topic. An overreliance on one sector could have harmful consequences for the competitiveness of the entire economy but sometimes also for the sector itself, particularly in the long run. We test several hypotheses in this context using two frameworks: a vector autoregression model with exogenous drivers and a vector error correction model, both built on quarterly time series data in the period ranging from 2000 to 2017 and validated out-of-sample on the 2018 and 2019 data. The results suggest that the macroeconomy appears to some extent forecastable by the performance of its automotive sector. This is further supported by the fact that the forecasting performance of the selected models looks reasonable. Likewise, the results show that the key variables proxying the performance of the automotive industry tend to converge to a long-run equilibrium or at least exhibit a long-run relationship with and/or vis-à-vis the selected macroeconomic indicators. This finding is in line with the fact that the automotive sector has an important position in the Czech economy also from a longer-term perspective. Yet, we have not found that the macroeconomy would be overreliant on automotives in general terms.

Implications for Central European audience: The text brings potential value for the Central European audience by drawing attention to the palpating discussion among policymakers, scientists, and the media about the reliance of the macroeconomy on the automotive sector. Hence, it suggests how independent individual economic policies may ultimately be, also depending on the share of the automotive industry on total output. It is also useful for the top management of the firms in the large automotive firms, be it producers or suppliers, as they may observe how the interconnections with the outer economy might look like. Likewise, for the banking sector, the paper disentangles potential issues with concentration risk and conveys information about industry-specific lending. Finally, the paper provides the Central European readers with information about how the linkages in the automotive industry can be viewed as a whole.

Keywords: automotive industry; macroeconomic performance; equilibrium JEL Classification: L62, E17, C3 


\section{Introduction}

Hence, the main objective of this paper is to fill in the gaps in the existing perception of the interdependence and mutual influencing between the economy and the local automotive industry. The article also attempts to answer the question to what extent it is possible to forecast the Czech economic growth based on the development of its automotive sector. Besides, the question of potential overreliance on automotives appears even more relevant in the context of the COVID-19 pandemic.

It should be noted that since this paper deals with the performance of the macroeconomy in relation to one of its key industries/sectors, the international comparison might easily hit its limits already in the early stages. This is mainly due to the fact that key industries vary depending on the selected geography, which can be clearly demonstrated on the European data. The inclusion of Germany as the Czech major trading partner partially mimics such an endeavour. Likewise, comparing economies with different production technologies would be misleading and probably lead to biases. Hence, in our research, we strive to compare what can be compared, i.e. similar economies with similar key industries that sometimes serve as a context for our analysis as well. Some economies from the CEE region qualify for that, e.g. Slovakia.

The rest of the article is structured as follows: Section 1 summarises the recent literature and quantitative research in the fields relevant to the topic. Section 2 presents data and hypotheses used throughout the rest of the article. Section 3 develops the models and summarises their results, including also the forecasting performance. The last section concludes the conclusion.

\section{Theoretical background}

A broad consensus exists in the economic literature that the automotive industry plays a significant role in the global and national economies (see Latorre \& Gómez-Plana, 2011; Orsato \& Wells, 2007). The automotive sector affects the economy not only via its magnitude and export share but also via ties with the other sectors and supply chains. Usually, the shock to the automotive sector affects suppliers of car components as well. This is particularly true for Central Europe, where a number of authors attempted to quantify its overall impact on GDP growth. For example, Babel'ová et al. (2010) stress the importance of the automotive industry in Slovakia, while Pavlínek (2017) focuses on the importance of the automotive industry in Central and Eastern Europe particularly in the context of the foreign direct investment. Likewise, the significance of the automotive industry in the Czech economy was studied, e.g. by Mohelský and Machková (2012), who pointed out potential caveats of automotive overdependence. The topic of the economic dependency on automotive sales was partly addressed by Sedláček (2013) but mainly in the context of the global economic crisis between 2007 and 2010. Elsewhere, Hong and Bo (2011) model also Chinese car sales forecasting using ARMA environment. Similarly, Kitapcı et al. (2014) employ neural networks to assess the impact of economic policies on the sale of automobiles in Turkey. An interesting contribution comes from Fantazzini and Toktamysova (2015), who use Google data and multivariate models to do the same in Germany. 
Likewise, not much quantitative research was devoted to the problem of the automotive industry in the Czech Republic and its repercussions for the macroeconomy. A notable exception is, again, Sedláček (2013), who uses standard correlation analysis with the help of Cohen's distance index to quantify the impact of the Global Financial Crisis on the Czech automotive sector. He concludes that the dependency is relatively strong. Elsewhere, authors employ univariate time series analysis, such as AR or MA processes, or their combinations, such as ARMA or ARIMA, to forecast the performance of the automotive sector (Böckers et al., 2012), but usually without further extensions and relatively inconclusive results.

\section{Research objective, methodology and data}

\subsection{Modelling choices}

In the case of this paper, model selection is made based on both the traditional as well as more recent literature. For example, Sims (1980) provides a critique of standard structural models that split variables into strictly exogenous and strictly endogenous and proposes prevalently data-driven autoregressive models where all variables are treated as endogenous. Although the use of VAR models in the analysis of double-dependency hypotheses is quite common, their formulation may sometimes be restrictive as they require that the entering variables be stationary to avoid spurious regression in line with the BoxJenkins methodology. A response, and sometimes a complement, to the traditional vector autoregression, lies in using non-stationary series when they are cointegrated, as per the methodology proposed by Engle and Granger (1987). Likewise, even a combination of stationary and non-stationary variables, or different orders of integration in the vector, should not always be a problem, as suggested by Lütkepohl (2005). Besides this, for example, Cochrane (1990) suggests that since some unit-root tests might generally be of low power, they are unfit to have a say about whether the series of interest is stationary at all. This is also why both VARX and VECM specifications may be used in such a case.

Elsewhere, DSGE models may be a solution if more complex set-ups or theoretical foundations are required, which is contingent on the availability of underlying data (Ilzetzki et al., 2013). Meanwhile, when analysing auto sales in a macroeconomic context, some authors put forth data mining methods based on LASSO or Optimal Variable Search (OLS) techniques (Brühl et al., 2009). Lastly, a popular method to assess the effects of changing policy regimes, such as fiscal shocks, zero nominal lower bounds, or exchange rate commitments, is difference-in-differences, or DID, (e.g. Jiménez et al., 2016). Since this text does not explicitly deal with any policy changes, DID models have not been considered.

\subsection{Current context}

With about a $5 \%$ share of the total value added and more than a $20 \%$ share of total manufacturing production, the automotive industry is one of the leading sectors in the Czech economy. The NACE groups for the automotive industry as subsets of total manufacturing used in this article are 'Manufacture of motor vehicles, trailers and semitrailers' and 'Manufacture of other transport equipment'. The share of manufacturing of final vehicles vs the non-vehicle production within the automotive sector is roughly 40 vs $60 \%$, respectively, according to the Czech Automotive Industry Association (2020). This is supported by the fact that all subsectors are linked directly or indirectly to each other and 
exhibit significant spill-overs. Likewise, the industry's share of total Czech exports varies between 22 and 25\%, according to the Czech Statistical Office, and several major players in the market export more than $80 \%$ of their total production. These shares are high compared to the EU average, although there are countries with even larger importance of the sector, e.g. Slovakia.

Our main hypotheses could be summarised as follows:

H1: Automotive sector in the Czech Republic significantly affects Czech macroeconomic variables.

H2: The relationship between the performance of the automotive sector and the domestic macroeconomy, including their cyclical behaviour, can be observed as a two-way relationship, thus further confirming the potential fragility of the economy to shocks occurring in the automotive sector itself.

H3: Convergence to a certain 'state of equilibrium' with respect to macroeconomic drivers can be observed for indicators proxying the automotive sector. The term 'equilibrium' of 'state of equilibrium' conventionally refers to the notion of a long-run relationship between selected series or a state towards which the variables tend to converge, such as a long-run share of one another.

To address these hypotheses, we developed two models combining macroeconomic determinants, sector-specific drivers, and autoregressive terms: vector autoregression with exogenous drivers and vector error correction model. The set of two models enables us to shed more light on the relationship between the automotive industry and macroeconomy.

\subsection{Data}

Based on the methodology used by Latorre and Gómez-Plana (2011), conventional macroeconomic theory, and data availability, we identified five main indicators describing the Czech automotive sector. These are listed in Table 1. Also, several macroeconomic variables are supposed to describe economic universum in the country and at least approximate external economic conditions. Unless explicitly indicated otherwise, we harvested the data for the period of 2000 until 2019, which makes it 80 quarterly observations from the Czech Statistical Office (CZSO), Eurostat, OECD, and/or IMF. Data for 2020 were not considered since they were not complete and/or final by the time of writing this article. The data between 2000 and 2017 were used for model development, while 2018 and 2019 were left for validation.

Table 1 | Industry and retail datasets
Auto_sales $=$ retail sales of motor vehicles and motorcycles, index $2015=100$
Auto_wage ${ }_{t}=$ average monthly salary in the automotive industry, ths. CZK
Auto_prod ${ }_{t}=$ manufacture of motor vehicles of all kinds, index $2015=100$
Auto_empl ${ }_{t}=$ employment in the automotive industry, ths.
Auto_reg ${ }_{t}=$ new passenger car registrations, ths.

Note: All indicators are reported as seasonally adjusted, and production indicators are also adjusted for calendar days. For all sub-indicators, we follow the logic of the CZ-NACE 29 classification. All indicators are reported on a seasonally adjusted basis and adjusted for calendar days, where 
necessary. A statistical summary of the variables is available upon request from the authors. The entire statistical inference included in the article was performed using RStudio and EViews statistical software.

Source: authors' own elaboration based on data from the Czech Statistical Office (CZSO), Eurostat, OECD, and/or IMF.

Table 2 | Czech macroeconomic indicators

\begin{tabular}{|c|}
\hline$G D P_{-}$real $l_{t}=$ gross domestic product in bil. $2010 \mathrm{CZK}$ \\
\hline Cons_real $t_{t}=$ private consumption in bil. $2010 \mathrm{CZK}$ \\
\hline Inv_real $=$ fixed capital formation in bil. 2010 CZK \\
\hline Imp_real $t_{t}=$ imports in bil. $2010 \mathrm{CZK}$ \\
\hline Unemr $r_{t}=$ unemployment rate, $\%$ labour force \\
\hline$N A I R U_{t}=$ non-accelerating inflation rate of unemployment, \% labour force \\
\hline$I P_{t}=$ total industrial production, index $2015=100$ \\
\hline 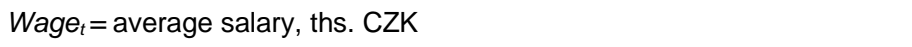 \\
\hline Sales $_{t}=$ total retail sales excl. automotive, bil. CZK. \\
\hline
\end{tabular}

Note: The NAIRU is estimated using the headline unemployment rate and Hodrick-Prescott filter extended with ARIMA forecast to reduce the usual end-point bias. This is its statistical estimation. However, the detailed theory behind NAIRU can be found, e.g. in Pošta (2008).

Source: authors' own elaboration based on data from the Czech Statistical Office (CZSO), Eurostat, OECD, and/or IMF.

Table 3 | Indicators approximating foreign demand and import content of Czech exports

Exp_real $t_{t}=$ exports in bil. 2010 CZK
GDP_real_Ger ${ }_{t}=$ gross domestic product of Germany in bil. 2010 EUR
Exp_real_Ger ${ }_{t}=$ exports of Germany in bil. 2010 EUR
Imp_real_Ger ${ }_{t}=$ imports of Germany in bil. 2010 EUR
GDP_real_WId ${ }_{t}=$ global gross domestic product in PPP, international dollars

Source: authors' own elaboration based on data from the Czech Statistical Office (CZSO), Eurostat, OECD, and/or IMF.

The variables represent a pool of available regressors covering industry-level detail, macroeconomic drivers such as GDP components, sectoral variables, and variables conventionally employed to detect mean reversion or convergence to equilibrium. Likewise, the set includes standard drivers recognised within the mainstream macroeconomic theory. Although two of the variables in the pool are nominal (Wage t $_{t}$ and Sales $s_{t}$ ), deflating them was rejected as this could introduce problems with selecting accurate deflators. Also, their usual stationary transformation further mitigates this issue and should restore the mean reversion of the series. 


\section{Results and discussion}

To proceed with the modelling, we first created a lag structure of the potential drivers, including a maximum of four quarterly lags for each variable and their stationary or close-tostationary transformations. In assessing the lag structure, we give less weight to more lags to account for the potential spuriousness of the data and reduce issues with data quality. Also, to account for the particularly high import content of the Czech automotive industry and to control for foreign demand, several external variables are included in the model. Those are Germany's GDP, its imports and exports, and the global GDP, as shown in Table 3. Note that Germany was selected as the most relevant economy representing foreign demand since it is the main trading partner of the Czech Republic with about one-third share on all trade volumes. Similarly, it has the second-highest share on all FDI inflows to the country.

Further, because of the expected simultaneity and distributed lag structure (DLS) of the variables describing the economy and the automotive sector, any simple regression was rejected as this would almost certainly entail a simultaneity bias. However, the static correlations between the main variables are shown in Table 4.

Table 4 | Pairwise correlation table for selected variables

\begin{tabular}{|c|c|c|c|c|c|c|c|c|c|c|c|c|c|}
\hline & & 1 & 2 & 3 & 4 & 5 & 6 & 7 & 8 & 9 & 10 & 11 & 12 \\
\hline 1 & $D\left(G D P \_r e a l_{t}\right)$ & 1.000 & & & & & & & & & & & \\
\hline 2 & $D($ Exp_real $)$ & 0.629 & 1.000 & & & & & & & & & & \\
\hline 3 & $D\left(\right.$ Unemr $\left.r_{t}\right)$ & 0.231 & 0.039 & 1.000 & & & & & & & & & \\
\hline 4 & $D\left(\right.$ Wage $\left._{t}\right)$ & 0.611 & 0.425 & -0.211 & 1.000 & & & & & & & & \\
\hline 5 & $D$ (Auto_sales $)$ & 0.541 & 0.217 & -0.032 & 0.382 & 1.000 & & & & & & & \\
\hline 6 & $\left.D(\text { Auto_wage })_{t}\right)$ & 0.256 & 0.099 & -0.018 & -0.421 & 0.324 & 1.000 & & & & & & \\
\hline 7 & $D$ (Auto_emplt) & 0.342 & -0.027 & -0.105 & -0.122 & 0.285 & 0.081 & 1.000 & & & & & \\
\hline 8 & $D($ Auto_reg $)$ & 0.473 & -0.142 & -0.042 & -0.156 & 0.223 & 0.452 & 0.221 & 1.000 & & & & \\
\hline 9 & $D$ (Auto_prodt) & 0.425 & -0.092 & -0.009 & 0.235 & -0.040 & 0.000 & 0.000 & 0.582 & 1.000 & & & \\
\hline 10 & $D\left(G D P \_r e a l \_W I d_{t}\right)$ & 0.580 & 0.372 & -0.017 & -0.228 & 0.241 & 0.402 & 0.652 & 0.118 & 0.320 & 1.000 & & \\
\hline 11 & $D(G D P$ real_Gert $)$ & 0.675 & 0.477 & -0.015 & 0.348 & 0.158 & 0.071 & 0.126 & 0.251 & 0.659 & 0.201 & 1.000 & \\
\hline 12 & $D\left(I m p \_r e a l \_G e r_{t}\right)$ & 0.775 & 0.512 & -0.027 & 0.411 & 0.189 & 0.112 & 0.220 & 0.423 & 0.611 & 0.680 & 0.351 & 1.000 \\
\hline
\end{tabular}

Note: 'D' stands for the first difference of the respective variable.

Source: authors

Finally, only the variables that show reasonable and intuitive covariance on the level and first difference are taken further for consideration. For every model, we make sure the model robustness is fulfilled and compliant with Gauss-Markov assumptions, Box-Jenkins methodology, and/or, the entering variables are potentially cointegrated (Juselius, 2006). 


\subsection{Vector autoregression with exogenous drivers}

As a first step, we employ the VAR methodology for the reasons mentioned earlier in the text. The VAR models are particularly useful when simultaneity biases, i.e. situations in which the explanatory variable is correlated with the error term of the regression, appear.

Since all variables included in a VAR model set-up are endogenous, it is difficult to interpret the individual coefficients with too much accuracy. Hence, we use impulse-response functions that demonstrate a one standard deviation shock to the explanatory variable to see how the effect on the dependent variable. Vector autoregressive models with exogenous drivers (VARX) are widely used for analysing multivariate time series. Original VAR models treat all variables as endogenous following the critique of Sims (1980) on the ad hoc exogeneity assumption of macroeconomic models. Still, VARX models can also incorporate restrictions and mute selected equations if necessary and may include exogeneity of some of the variables ('external drivers'). They can also be amended to include deterministic terms. Typical VARX models are used for modelling and forecasting the dynamic behaviour of economic and financial time series, including evaluation of policies and structural inference. The basic $\operatorname{VAR}(p)$ model is defined by the following equation:

$$
y_{t}=A_{1} y_{t-1}+\ldots+A_{p} y_{t-p}+u_{t}
$$

where $A_{i}$ are $(\mathrm{K} \times \mathrm{K})$ coefficient matrices, and $u_{t}$ is a $\mathrm{K}$ dimensional white noise process with $E\left(u_{t}\right)=0$ and $E\left(u_{t} u_{t}^{T}\right)=\sum u$. The $\operatorname{VARX}(\mathrm{p})$ model needs to be a stationary process with time-invariant mean, variance and covariance structure, otherwise, its assumptions would be violated. Clearly, after the inclusion of exogenous drivers in the model, with not a priori restricted number, the equation for a VARX changes as follows:

$$
y_{t}=A_{1} y_{t-1}+\ldots+A_{p} y_{t-p}+B_{1} X_{t-1}+\ldots+B_{p} X_{t-p}+u_{t}
$$

where $X_{t}$ represents the vector of exogenous variables and $B_{1}$ are coefficient matrixes for external drivers. The coefficients of the $\operatorname{VARX}(p)$ process can be estimated by applying OLS to each of the equations. The OLS estimator is identical to the generalised least squares estimator, or GLS, if and only if there are no restrictions in the parameters. The usual statistical inference procedures are imposed when the process is stable. As was shown earlier, in case there are integrated variables so that $y_{t} \sim I(1)$, then the process is unstable, and the variables may be cointegrated. The usual estimation methods can still be applied for estimating the model parameters, but the usual $t-$ and $F$ tests may lead to misleading conclusions when used for hypothesis testing. VARX can also be represented in the structural form if restrictions are imposed on model parameters, that is, elements of $A$ matrix, B matrix or both matrices in the equation above.

The following Table 5 presents unit root tests for the variables in question. It is readily apparent that, with the notable exceptions of the real household consumption and NAIRU, all variables are integrated of order 1 , or I(1), at $5 \%$ significance level. That also implies that all variables in the dataset are non-stationary. 
Table 5 | Unit root testing - Augmented Dickey-Fuller

\begin{tabular}{|c|c|c|c|c|c|}
\hline Variable & $T$-stat & Prob. & Variable & $T$-stat & Prob. \\
\hline GDP_real & -1.336 & 0.609 & $\mathrm{D}\left(\mathrm{GDP} \_r e a l_{t}\right)$ & -3.258 & $0.021^{* *}$ \\
\hline Cons_real & -1.487 & 0.535 & $\mathrm{D}\left(\right.$ Cons_real $\left.\mathrm{t}_{\mathrm{t}}\right)$ & -2.508 & 0.118 \\
\hline Invest_real ${ }_{t}$ & -1.795 & 0.380 & $\mathrm{D}$ (Invest_real $\left.\mathrm{t}_{\mathrm{t}}\right)$ & -7.618 & $0.000^{* * *}$ \\
\hline Imp_real & -1.014 & 0.745 & $\mathrm{D}\left(\left.\mathrm{Imp} \_r e a\right|_{t}\right)$ & -7.686 & $0.000^{* * *}$ \\
\hline Wage $_{t}$ & -1.047 & 0.733 & $\mathrm{D}\left(\mathrm{Wage}_{\mathrm{t}}\right)$ & -2.901 & $0.049^{\star *}$ \\
\hline Auto_prod ${ }_{t}$ & -0.855 & 0.797 & $\mathrm{D}\left(\right.$ Auto_prod $\left.\mathrm{t}_{\mathrm{t}}\right)$ & -7.929 & $0.000^{\star * *}$ \\
\hline Auto_sales & -1.285 & 0.628 & $\mathrm{D}$ (Auto_sales $\mathrm{t}$ ) & -2.841 & $0.049^{\star *}$ \\
\hline Auto_wage $_{t}$ & -1.126 & 0.702 & $\mathrm{D}\left(\right.$ Auto_wage $\left._{t}\right)$ & -6.601 & $0.000^{* * *}$ \\
\hline Auto_empl & -1.304 & 0.624 & $\mathrm{D}$ (Auto_empl $\mathrm{t}$ ) & -2.852 & $0.046^{\star *}$ \\
\hline Auto_reg ${ }_{t}$ & -1.746 & 0.404 & $\mathrm{D}($ Auto_reg $\mathrm{t})$ & -4.064 & $0.002^{* * *}$ \\
\hline Sales $_{t}$ & -1.246 & 0.651 & $\mathrm{D}\left(\right.$ Sales $\left._{\mathrm{t}}\right)$ & -2.265 & $0.047^{\star *}$ \\
\hline$I P_{t}$ & -0.473 & 0.890 & $\mathrm{D}\left(\mathrm{IP} \mathrm{P}_{\mathrm{t}}\right)$ & -3.345 & $0.016^{\star *}$ \\
\hline Unemr $r_{t}$ & -8.859 & $0.000^{* * *}$ & $\mathrm{D}\left(\right.$ Unemr $\left._{\mathrm{t}}\right)$ & -10.501 & $0.000^{* * *}$ \\
\hline $\mathrm{NAIRU}_{\mathrm{t}}$ & 0.366 & 0.980 & $\mathrm{D}\left(\mathrm{NAIRU}_{\mathrm{t}}\right)$ & -2.000 & 0.285 \\
\hline Exp_real $_{t}$ & -0.809 & 0.811 & $\mathrm{D}\left(\mathrm{Exp}_{\mathrm{f}}\right.$ real $\left.\mathrm{I}_{\mathrm{t}}\right)$ & -7.509 & $0.000^{* * *}$ \\
\hline GDP_real_Ger ${ }_{t}$ & -0.262 & 0.925 & D(GDP_real_Gert) & -6.578 & $0.000^{* * *}$ \\
\hline Exp_real_Ger ${ }_{t}$ & -0.769 & 0.822 & D(Exp_real_Ger $\left.{ }_{t}\right)$ & -6.909 & $0.000^{\star * *}$ \\
\hline Imp_real_Ger ${ }_{t}$ & -0.334 & 0.914 & $\mathrm{D}\left(\mathrm{Imp}\right.$ real_Ger $\left.{ }_{\mathrm{t}}\right)$ & -8.258 & $0.000^{* * *}$ \\
\hline GDP_real_Wld & -0.281 & 0.937 & $\mathrm{D}(\mathrm{GDP}$ _real_Wld $)$ & -7.185 & $0.000^{\star * *}$ \\
\hline
\end{tabular}

Note: 'D' denotes first difference; $p$-values are in parentheses; asterisks “***”, "**” and "*” indicate significance at $1 \%, 5 \%$, and $10 \%$ level, respectively.

Source: authors

For the sake of consistency, we took percentage differences of all variables in question, with the notable exception of the unemployment rate, where percentage change does not have a sensible interpretation. Based on the selection procedure using correlation matrix, perceived quality of the data, available literature as well as our initial research questions, q- 
o-q percentage change in Auto_prodt and q-o-q percentage change in GDP_realt were retained as the endogenous variables, while the quarterly difference in (Unemrt - NAIRUt), q-o-q percentage change in Wages, and q-o-q percentage change in Imp_real_Gert play roles of external drivers (partially based on Asiedu, 2002; Auerbach \& Gorodnichenko, 2013). While the domestic demand side is proxied by the situation in the labour market, foreign demand is approximated by real Germany's imports. Other variables listed in Table 2 were not considered due to low covariances, high standard errors and/or issues with collinearity.

The system of equations for the unrestricted VARX model used in our estimation can be written as follows:

$$
\begin{aligned}
& P C_{\text {gdp_real } t}=\text { const }++a_{1} P C_{\text {gdp_real } t-n}+a_{2} P C_{\text {auto_prod } t-n}+a_{3} P C_{\text {wage } t-n}+a_{4} \text { diff } f_{\text {unemr }- \text { nairu } t-n}+a_{5} P C_{\text {imp_real_ger t-n }} \\
& P C_{\text {auto_prod } t}=\text { const }++a_{1} P C_{\text {auto_prod } t-n}+a_{2} P C_{\text {gdp_real } t-n}+a_{3} P C_{\text {wage } t-n}+a_{4} \text { diff } f_{\text {unemr-nairu } t-n}+a_{5} P C_{\text {imp_real_ger } t-n},
\end{aligned}
$$

where each respective term $t-n$ stands for a finite number of lags determined by the standard information criteria (AIC, SC, and $\mathrm{HQ}$, respectively), as shown in Table 6. Since Akaike and Schwarz criteria point to the same number of lags (3) and Hannan-Quinn selects 2, we have opted for three lags to be included. The likelihood ratio for three lags is also the lowest out of all potential lags tested in the model.

Table 6 | Selection of lag length in the VARX Model

\begin{tabular}{cccc}
\hline Lag & AIC & SC & HQ \\
\hline 0 & 17.258 & 18.042 & 17.797 \\
1 & 19.140 & 19.594 & 19.394 \\
2 & 18.125 & 18.525 & $18.281^{*}$ \\
3 & $16.367^{*}$ & $18.417^{*}$ & 18.301 \\
4 & 17.558 & 18.128 & 17.920 \\
5 & 19.921 & 19.992 & 19.952 \\
\hline
\end{tabular}

Note: the minimum value is marked with an asterisk

Source: authors

Before proceeding with estimation itself, we have conducted an impulse-response analysis (IRF) of the two endogenous variables included in the VAR model. The results can be observed in Figures 1 and 2. 
Figure 1 | Orthogonal impulse response from automotive production to real GDP

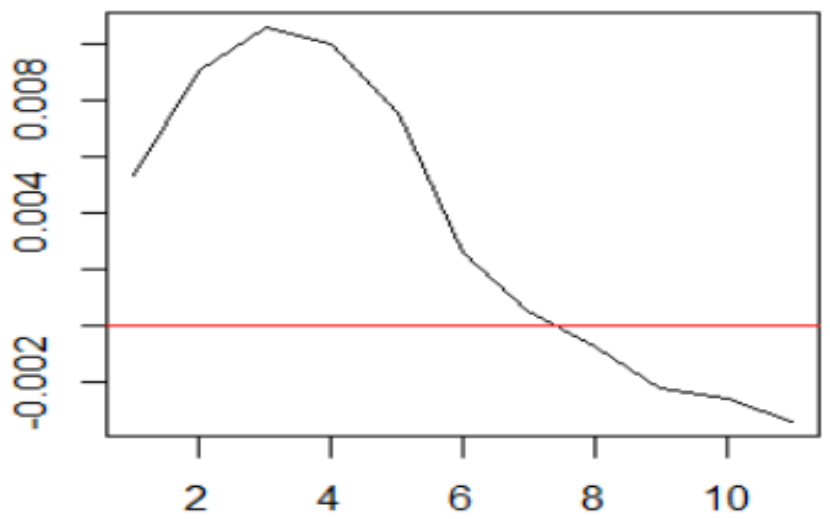

Note: IRF performed on annual percentage changes

Source: authors

Figure 2 | Orthogonal impulse response from real GDP to automotive production

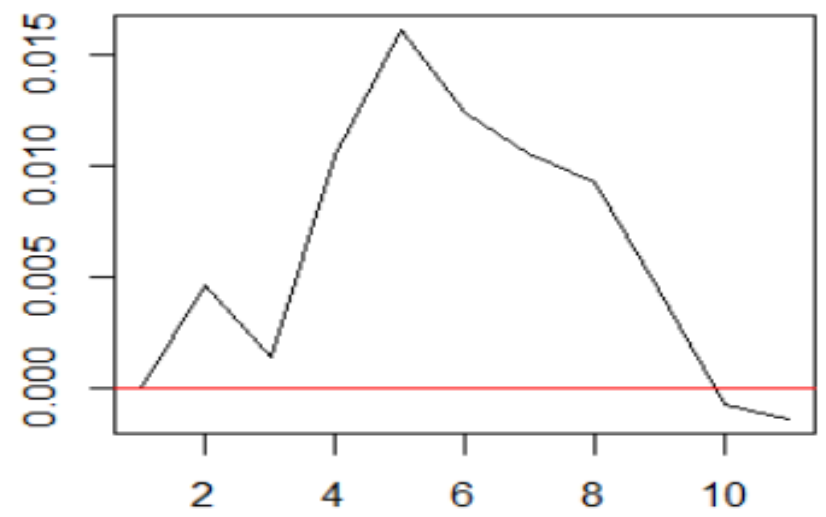

Note: IRF performed on annual percentage changes

Source: authors

As can be noted, the shock to automotive manufacture variable has a relatively long and persistent propagation in GDP. The decay is slow and happens after about eight periods. The impulse from GDP has a stronger immediate effect on automotive manufacturing but is also more ambiguous as the sign turns negative after two periods and then becomes more intuitive again. The decay is faster but the series exhibits some more amplification than in the first case.

The estimation output of our VARX model is shown in Tables 7 and 8 . The optimal number of lags for endogenous variables is three quarters, while exogenous variables have either three or two quarters to achieve optimal fit (always shown in the brackets). Clearly, the value of the coefficients should be regarded with caution as they are not directly 
interpretable due to endogeneity of all variables in the model. However, the signs are intuitive and broadly consistent with the IRF.

Table 8 | VARX estimation output: automotive production as dependent variable

\begin{tabular}{|c|c|c|c|c|}
\hline & & coeff. & s.e. & t-st. \\
\hline \multicolumn{2}{|l|}{ Constant } & 0.70 & 0.63 & 1.12 \\
\hline \multicolumn{2}{|c|}{ PC_GDP_real (-1) } & 0.28 & 0.13 & 2.43 \\
\hline \multicolumn{2}{|c|}{ PC_GDP_real (-2) } & 0.22 & 0.12 & 1.74 \\
\hline \multicolumn{2}{|c|}{ PC_GDP_real (-3) } & -0.11 & 0.33 & -0.28 \\
\hline \multicolumn{2}{|c|}{ PC_Auto_prod (-1) } & 0.23 & 0.22 & 1.03 \\
\hline \multicolumn{2}{|c|}{ PC_Auto_prod (-2) } & 0.38 & 0.16 & 2.46 \\
\hline \multicolumn{2}{|c|}{ PC_Auto_prod (-3) } & -0.22 & 0.20 & -1.20 \\
\hline \multicolumn{2}{|l|}{ PC_Wage (-3) } & 0.10 & 0.91 & 0.11 \\
\hline \multicolumn{2}{|c|}{$\operatorname{diff}($ Unemr - NAIRU) (-2) } & -0.11 & 0.81 & -0.14 \\
\hline \multicolumn{2}{|c|}{ PC_Imp_real_Ger (-3) } & 0.80 & 0.38 & 2.07 \\
\hline Adj. R-squared & 0.3342 & & & \\
\hline Sum sq. resids & 152.0024 & & & \\
\hline S.E. equation & 1.9496 & & & \\
\hline F-statistic & 10.0228 & & & \\
\hline Log likelihood & -136.1082 & & & \\
\hline
\end{tabular}

Sample (adjusted): 2003Q1 2017Q4

Obs.: 60 after adjustments

Note: lags for exogenous drivers preselected

Source: authors

Based on the above estimation output for the previously introduced VARX model, we confirm mutual dependency of the automotive sector and Czech macroeconomic performance once we also control for exogenous drivers. The lag structure indicates that the dynamics of the real GDP in the Czech Republic changes with about one- or twoquarter delay to the dynamics of the automotive sector and that the link appears to be marginally stronger from the automotive sector to macro indicators than vice versa. The automotive production accelerates two quarters after acceleration of Czech macroeconomic performance but to a somewhat lesser extent than in the opposite direction. Finally, most 
coefficients are as expected, and those with shorter lags typically exhibit higher statistical significance.

\subsection{Vector error correction model}

In what follows, we deploy an approach that has become increasingly popular in the field of econometrics in case the series are non-stationary but cointegrated at the same time, and their differencing may not be desirable as it entails scrapping valuable pieces of information about their long-term behaviour (Juselius, 2006). This model set-up enables us to explore the adjustment process from a short-run fluctuation to long-run equilibrium. Also, this permits to make more use of underlying economic theory and bring back important information about transitory disequilibria.

Based on the Johansen test for cointegration (Österholm \& Hjalmarsson, 2007), which has the advantage of testing all possible cointegrated relationships compared to the EngleGranger procedure, we identified four variables, all of which were I(1), i.e. had the same order of integration of one: Auto_salest, Auto_prodt, GDP_realt, and IPt. To obtain more efficient estimates, we had to identify a number of cointegrating relationships in the originally defined VAR model, i.e. the one with the same selected variables. However, since the power of all tests employed to determine those is questionable, both frameworks were ultimately used. These variables are assumed to drift to a long-run equilibrium relative to each other (Pesaran et al., 2002). The long-term equilibrium can be co-determined by capacity constraints present in the Czech automotive industry and/or may mean-revert to a long-term share relative to underlying macroeconomic factors. For that matter, we constructed a simple Vector Error Correction Model, or Cointegrated VAR, which enables to use a vector autoregression on multivariate and integrated time series.

According to Juselius (2006), one possibility of how we can write a VECM in its generalised form with a lag order $\mathrm{n}$ is as follows:

$\Delta x_{t}=\alpha \beta^{\prime} x_{t-1}+\Gamma_{1} \Delta x_{t-1}+\cdots+\Gamma_{n-1} \Delta x_{t-n-1}+\mu+A_{1} y_{1, t}+\cdots+A_{m} y_{m, t}+u_{t}$,

where $x_{t}$ is a vector of the four variables as specified previously, with $\Gamma_{1}, \ldots, \Gamma_{n-1}$ as $4 \times 4$ coefficient matrices. Further, the constant term is defined as $\mu$, while the usual error correction part lies in the term $\alpha \beta^{\prime} x_{t-1}$, with $\alpha$ being the speed of adjustment to equilibrium. Meanwhile, $\beta$ denotes a long-term equilibrium value, and $u_{t}$ is the error term. Finally, $y_{m, t}$ stands for the vectors of individual exogenous variables in the model (in case they are included) and $A_{m}$ represent their respective coefficients (coefficient vectors). It is important to note that the convergence may also exhibit dynamic equilibrium when the convergence happens over time but is actually never accomplished. In such a case, long-term equilibrium is a sort of perpetual process. We have not, however, attempted to obtain equilibrium values by filtering the series or a Markov switching approach, suggested, e.g. in Christiano and Fitzgerald (1999) or French (2001) as this would be beyond the scope of this article.

Similarly, although we originally tested inclusion of (regime) dummy variables for the period of the GFC (2007-2009) as well as the ensuing European sovereign debt crisis (with the usual timeframe of 2010 and 2014), we do not use any exogenous variable in this model set-up. Based on the usual information criteria, we selected the maximum of one quarterly 
lag for the entire model based on minimising the AIC criterion. This also appears to be a reasonable number given the number of parameters and quarterly granularity of the data.

As can be observed in the following Table 9, the Johansen maximum likelihood method indicates maximum of three cointegrated equations at the $5 \%$ significance level, using both the trace and eigenvalue statistics (which are usually correlated).

Table 9 | Unrestricted Cointegration Rank Test

\begin{tabular}{|lllll|}
\hline $\begin{array}{l}\text { Hypothesised } \\
\text { Number of CE }\end{array}$ & Eigenvalue & Trace Stat. & Critical Value & Prob. \\
\hline None & 0.241 & 48.521 & 38.212 & 0.00 \\
Maximum 1 & 0.152 & 21.521 & 18.960 & 0.04 \\
Maximum 2 & 0.137 & 17.568 & 17.253 & 0.05 \\
Maximum 3 & 0.082 & 8.125 & 9.781 & 0.07 \\
\hline $\begin{array}{l}\text { Hypothesised } \\
\text { Number of CE }\end{array}$ & Eigenvalue & $\begin{array}{l}\text { Max-Eigen } \\
\text { Statistic }\end{array}$ & Critical Value & Prob. \\
\hline $\begin{array}{l}\text { None } \\
\text { Maximum 1 }\end{array}$ & 0.241 & 35.120 & 38.212 & 0.00 \\
Maximum 2 & 0.152 & 14.203 & 11.201 & 0.03 \\
Maximum 3 & 0.082 & 11.412 & 9.102 & 0.04 \\
\hline
\end{tabular}

Source: authors

The following Table 10 shows the positive long-term relationship between the real GDP, auto sales, and auto production.

Table 10 | VECM Estimation Output

\begin{tabular}{|c|c|c|c|c|}
\hline & Auto_prod ${ }_{t}$ & GDP_real $t$ & Auto_sales ${ }_{t}$ & $I P_{t}$ \\
\hline Auto_prod & & $\begin{array}{l}0.661^{* * *} \\
(0.000)\end{array}$ & $\begin{array}{l}0.757^{* * *} \\
(0.000)\end{array}$ & $\begin{array}{l}0.784^{* * *} \\
(0.000)\end{array}$ \\
\hline$G D P_{\text {real }}{ }_{t}$ & $\begin{array}{l}0.345^{\star * *} \\
(0.000)\end{array}$ & & $\begin{array}{l}0.399^{* * *} \\
(0.000)\end{array}$ & $\begin{array}{l}0.356^{* * *} \\
(0.000)\end{array}$ \\
\hline Auto_sales $t_{t}$ & $\begin{array}{l}0.253^{\star * *} \\
(0.004)\end{array}$ & $\begin{array}{l}0.125^{\star \star \star} \\
(0.001)\end{array}$ & & $\begin{array}{l}0.437^{\star \star \star} \\
(0.001)\end{array}$ \\
\hline$I P_{t}$ & $\begin{array}{l}0.289^{* *} \\
(0.041)\end{array}$ & $\begin{array}{l}0.220^{* *} \\
(0.047)\end{array}$ & $\begin{array}{l}0.093^{* *} \\
(0.034)\end{array}$ & \\
\hline Adj. R-sq. & 0.542 & 0.559 & 0.581 & 0.553 \\
\hline F-test (model) & 10.122 & 9.271 & 5.713 & 8.277 \\
\hline Obs. & 60 & 60 & 60 & 60 \\
\hline $\begin{array}{l}\text { Sample } \\
\text { (adjusted): }\end{array}$ & 2003Q1 2017Q4 & & & \\
\hline
\end{tabular}

Note: $p$-values in parentheses

Source: authors 
As can be seen, the VECM set-up works in a satisfactory manner and is generally stable. It shows how each series reacts to the most recent disequilibrium value between itself and the other series in the system. We can assert that both variables representing the automotive industry, i.e. automotive retail sales and automotive production, are linked to the macroeconomy in the long run, as they have expected signs and are statistically significant. Meanwhile, overall industrial production is significantly influenced by the automotive variables. Still, this could be driven by the hidden endogeneity in the two variables as car production is part of the manufacturing production, which is, in turn, the major component of industrial production. For GDP, we can observe a somewhat weaker link, but still statistically significant. Obviously, the inclusion of IPt was mainly motivated to demonstrate how the automotive production tends or converges to a certain stable share on the industrial production. Clearly, both sales and production have a tendency to converge to certain equilibrium levels vis-à-vis macroeconomic aggregates and move in sync with them. The strength of influence cannot be judged upon with certainty in this model environment, but the model confirms the long-term mutual convergence of these series and the macroeconomy.

\subsection{Forecasting performance}

To assess how the models perform in terms of predictions, we calculated out-of-sample mean absolute percentage error or MAPE, and the root mean square error, or RMSE. Also, we added an ARIMA specification as a benchmark model. The results can be seen in Table 11. The accuracy is assessed on the quarterly values for the period of 2018 and 2019. As can be seen, in terms of RMSE as well as MAPE, the VECM outperforms both the ARIMA and VARX models.

Table 11 | Forecasting performance

\begin{tabular}{lll}
\hline Model & MAPE & RMSE \\
\hline ARIMA & 0.198 & 14.058 \\
VARX & 0.156 & 13.362 \\
VECM & 0.143 & 10.012
\end{tabular}

Note: the out-of-sample period ranges from Q1 2018 until Q4 2019.

Source: authors

Hence, the results further suggest that the model combining short-run fluctuations and longrun tendency might fit the data reasonably well, which is also in line with our expectations.

\section{Conclusion}

We presented two benchmark models capturing the performance of selected variables 'representing' the automotive sector in the Czech Republic with respect to the most relevant macroeconomic phenomena. The aim of the exercise was to test the three main hypotheses stated at the beginning of the section. 
Hence, with the aid of the former, we can conclude as follows:

H1: Automotive sector in the Czech Republic significantly affects Czech macroeconomic variables. According to both models, the automotive sector is strongly linked to domestic macroeconomic variables but also to foreign demand. Yet, not all macroeconomic drivers, including those from abroad, unless accounted for the spill-overs into the domestic economy, have a direct effect on the Czech automotive industry. Such a conclusion is broadly in line with the data on where most of the final output from the Czech automotive sector eventually goes. The limitation here is that the output (product) of the automotive industry adds up to a non-negligible share of the Czech GDP variable.

H2: The linkage between the performance of the automotive sector and the domestic macroeconomy, including their cyclical behaviour, can be observed as a two-way relationship, thus further confirming the potential fragility of the economy to shocks occurring in the automotive sector itself. The relationship between the performance of automotive and the macroeconomy can be observed from both sides. Its lag distribution is, however, different and likely follows economic phenomena that were not tested any further in this article, such as spill-overs to other economic sectors. Still, with a high level of confidence, we may assert that any shocks to the automotive sector flow into the dynamics of the Czech macroeconomy with a delay of a maximum of two quarters. In the same vein, shocks to a non-automotive part of the economy would hurt the automotive sector to a limited extent, too. Also, the tested lag structure reveals a relatively short reaction of the Czech GDP to changes in the automotive sector of a maximum of two quarters and a similar opposite direction. Yet, we may assert that although the performance of the automotive sector is important for the general economic performance, the frequently used term 'dependency' of the Czech economy on the automotive sector would be too much to use. This is mainly visible from the VAR estimation but also from the fact that the VECM model results are relatively stable.

H3: Convergence to a certain 'state of equilibrium' with respect to macroeconomic drivers can be observed for indicators proxying the automotive sector. From our estimations, it appears that at least selected variables representing the automotive industry, sales and production, tend to converge to certain equilibrium levels vis-à-vis macroeconomic aggregates or indicators. From that perspective, we can observe a longterm relationship between selected macro drivers and those selected from the automotive sector. However, for a more complete and accurate assessment, a longer time span would be needed, especially given the volatility of car production and the Global Financial Crisis in 2008-2009. Likewise, we have not tested any regime-switching set-up and didn't include dummy variables for different time periods as no clear-cut growth regimes could be observed in history. With more data coming in in the future, such differentiation will likely become possible.

In this paper, we have extended the current knowledge of the correlation between the performance of the automotive industry and economic performance. Based on the results, we can confirm possible, yet limited, predictability of the economy based on the development of the automotive industry, and also confirm that the selected variables representing the automotive industry tend to converge to certain equilibrium levels in relation to the macroeconomic aggregates and indicators. The replicability of such research 
elsewhere is contingent on the structure and share of the automotive sector in the geography in question.

The limitation of the conducted research resides in the fact that quarterly data were used instead of, for example, monthly ones. Still, using monthly data could be challenging since particularly main macroeconomic drivers are not reported with monthly regularity for methodological as well as reasons. This can be likely improved once more reliable highfrequency proxies for macroeconomic drivers get released by public sources in the future.

\section{Acknowledgement}

The authors disclose receiving Institutional support for long-term strategic development from the research institute at the University of Finance and Administration in Prague.

\section{References}

Asiedu, E. (2002). On the determinants of foreign direct investment to developing countries. Is Africa different? World Development Journal, 30(1), 107-119. https://doi.org/10.2139/ssrn.280062

Auerbach, A. J., \& Gorodnichenko, Y. (2013). Output spillovers from fiscal policy. The American Economic Review, 103(3), 141-146. https://doi.org/10.1257/aer.103.3.141

Babel'ová, Z. G., Lenhardtová, Z., Cagáňová, D., \& Weidlichová-Luptáková, S. (2010). Importance of projects in automotive industry. Research Papers Faculty of Materials Science and Technology Slovak University of Technology, 18(28), 89-94. https://doi.org/10.2478/v10186-010-0011-5

Böckers, V., Heimeshoff, U., \& Müller, A. (2012). Vorsprung durch Technik: Empirical evidence of the German Scrappage program. VfS Annual Conference 2012 (Goettingen): New Approaches and Challenges for the Labor Market of the 21st Century. https://www.econstor.eu/bitstream/10419/62043/1/VfS_2012_pid_993.pdf

Brühl, B., Hülsmann, M., Borscheid, D., Friedrich, C. M., \& Reith, D. (2009). A sales forecast model for the German automobile market based on time series analysis and data mining methods. In P. Perner (Ed.), Advances in data mining: Applications and theoretical aspects. Lecture Notes in Computer Science, Vol. 5633 (pp. 146-160). Springer. https://doi.org/10.1007/978-3-64203067-3_13

Christiano, L. J., \& Fitzgerald, T. J. (1999). The Band Pass Filter. NBER Working Papers, No. 7257, https://doi.org/10.3386/w7257

Cochrane, J. H. (1990). A critique of the application of unit root tests. Journal of Economic Dynamics and Control, 15(2), 275-284, https://doi.org/10.1016/0165-1889(91)90013-Q

Czech Automotive Industry Association. (2020, October 9). Statistics. https://autosap.cz/en/statistics/

Engle, R. F., \& Granger, C. W. J. (1987). Cointegration and error correction: Representation, estimation and testing. Econometrica, 55(2), 251-276, https://doi.org/10.2307/1913236

Fantazzini, D., \& Toktamysova, Z. (2015). Forecasting German car sales using Google data and multivariate models. International Journal of Production Economics, 170(A), 97-135, https://doi.org/10.1016/j.ijpe.2015.09.010

French, M. W. (2001). Estimating changes in trend growth of total factor productivity: Kalman and H-P filters versus a Markov-Switching framework. SSRN Electronic Journal. https://doi.org/10.2139/ssrn.293105 
Hong, D., \& Bo, C. (2011). Sale forecasting method in dynamic environment based on ARMA(1,1). IEEE 2011 International Conference on Electric Information and Control Engineering (ICEICE) (pp. 4445-4448). https://10.1109/ICEICE.2011.5777454

Ilzetzki, E., Mendoza, E. G., \& Végh, C. A. (2013). How big (small?) are fiscal multipliers? Journal of Monetary Economics, 60(2), 239-254. https://doi.org/10.1016/j.jmoneco.2012.10.011

Jiménez, J. L., Perdiguero, J., \& García, C. (2016). Evaluation of subsidies programs to sell green cars: Impact on prices, quantities and efficiency. Transport Policy, 47, 105-118. https://doi.org/10.1016/j.tranpol.2016.01.002

Juselius, K. (2006). The cointegrated VAR model. Oxford University Press

Kitapcı, O., Ozekicioglu, H., Kaynar, O., \& Taştan, S. (2014). The effect of economic policies applied in Turkey to the sale of automobiles: Multiple regression and neural network analysis. Procedia Social and Behavioral Sciences, 148, 653-661. https://doi.org/10.1016/j.sbspro.2014.07.094

Latorre, M. C., \& Gómez-Plana, A. G. (2011). Multinationals in the Czech motor vehicles industry: A general equilibrium analysis for a transition economy. Europe-Asia Studies, 63(8), 1425-1447, https://doi.org/10.1080/09668136.2011.601114

Lütkepohl, H. (2005). New introduction to multiple time series analysis. Springer, https://doi.org/10.1007/978-3-540-27752-1

Mohelský, L., \& Machková, H. (2012). Is diversification as a strategic advantage? The example of automotive components in the Czech Republic. Central European Business Review, 1(2), 3745. https://doi.org/10.18267/j.cebr.16

Orsato, R. J., \& Wells, P. (2007). The automobile industry \& sustainability. Journal of Cleaner Production, 15(11), 989-993. https://doi.org/10.1016/j.jclepro.2006.05.035

Österholm, P., \& Hjalmarsson, E. (2007). Testing for cointegration using the Johansen methodology when variables are near-integrated. IMF Working Papers, 2007(141), 1-19. https://doi.org/10.5089/9781451867053.001

Pavlínek, P. (2017). Dependent growth: Foreign investment and the development of the automotive industry in East-Central Europe. Springer.

Pesaran, H., Schuermann, T., \& Weiner, S. M. (2002). Modelling regional interdependencies using a global error-correcting macroeconomic model. Journal of Business \& Economic Statistics, 22(2), 129-162. https://doi.org/10.1198/073500104000000019

Pošta, V. (2008). NAIRU a prírozená míra nezaměstnanosti - teoretický pohled. Ministerstvo financí ČR (NAIRU and the Natural Rate of Unemployment - Theoretical View), Výzkumná studie (Research Paper) 1/2008. https://www.mfcr.cz/cs/o-ministerstvu/odborne-studie-avyzkumy/2009/vyzkumne-studie-9446

Sedláček, M. (2013). Impact of the global crisis period 2007-2010 on the automotive industry in the Czech Republic. Journal of Competitiveness, 2(5), 108-123, https://doi.org/10.7441/joc.2013.02.08.

Sims, C. A. (1980). Macroeconomics and reality. Econometrica, 48(1), 1-48, https://doi.org/10.2307/1912017.

The research paper passed the review process. | Received: March 11, 2021; Revised: May 17, 2021; Accepted: June 6, 2021; Pre-published online: September 12, 2021; Published in the regular issue: May 19, 2022. 